\title{
Experimental investigation of the drying behaviour of the building materials
}

\author{
Jianhua Zhao ${ }^{1, *}$, Frank Meissener ${ }^{2}$, John Grunewald ${ }^{2}$, Shuo Feng ${ }^{3}$ \\ ${ }^{1}$ Institute of Architectural Technology \& Science, School of Architecture, Tianjin University, Tianjin, China \\ ${ }^{2}$ Institute of Building Climatology, Technische Universität Dresden, Germany \\ ${ }^{3}$ Qinhuangdao Municipal Bureau of Foreign Affairs and Commerce, Qinhuangdao, China
}

\begin{abstract}
The drying process gives an important insight for material characterization, during which the material experiences the moisture changing from saturation until the equilibrium with the environment, thus it sends both the liquid and vapor transport information. Drying in the material is a complex process that involves the simultaneous heat and moisture transfer. Due to its complex mechanism, currently there is no stipulation/rules on standardizing the drying test procedure of the moist building materials. In this paper, the drying behaviours of two building materials, ceramic brick and calcium silicate, are experimentally investigated. Different factors that influence their drying behaviours are explored. The approaches to assess the drying rate in two drying phases are also compared and discussed.
\end{abstract}

\section{Introduction}

Moisture related issues influence the durability of the building components, e.g., condensation and frost damage. It may also induce the healthy issue of the residents, e.g., mould growth. The deteriorating risk might become more severe in case of energy-efficiency renovation of historical buildings with application of internal insulation, due to the reduced drying potential of the wall assembly (Zhao 2017). Thus, many efforts have been attempted to control the moisture in the building components and avoid the potential deficiency. One of the prerequisites to achieve the success of those efforts is to well understanding the mechanism of moisture transfer in the building material and to quantify the moisture under a certain condition/environment. The moisture existing in the buildings always experiences a dynamic cycle of wetting, storaging and drying process. Distinct to other standardized tests, e.g., water absorption, there are no general stipulations/rules to standardize the drying procedure of the building materials due to manifold reasons.

The drying process is especially important for material characterization since it provides both the liquid and vapor transport information at different moisture content ranges. The drying behaviour of the building materials is influenced by many factors: environmental condition and material itself. The environmental factors include the surrounding temperature, humidity and air velocity. Moisture storage and transport characters of the material, together with its thermophysical property, will also affect the drying rate (Kaya et al. 2006).

Researchers from various fields have studied the drying behaviours for different purposes, e.g., agriculture, clothing, and building science. The description on the drying behaviour can be classified into three groups: numerical modelling with differential equations, analytic modelling with approximation of drying course, and drying coefficient.

(1) Drying process involves the simultaneus heat and moisture transfer. Numerical modeling of drying phenomena of the moist materials has been developed and implemented with the governing differential equations (Murugesan et al. 1996; Dietl et al. 1998; Janetti et al. 2018). One or two-dimensional simulations are further expanded to study the heat and moisture phenomena in 3D with the combination of CFD and HAM model. To include the variable boundary conditions, Kaya et al. (2006) and Belleghem et al. (2014) applied CFD to determine the convective heat and mass transfer coefficient distributions on the drying surface, in order to calculate temperature and moisture distributions in the material at different time periods.

(2) Some researchers seek to describe the drying process by linear or exponential functions (Sanderet al. 2000). Jurk et al. (2004) and Barreira et al. (2014) evaluated different models suitable to estimate the dry course of different materials. Karagiannis et al. (2017) applied a first-order model to describe the drying process of the capillary absorbed water based on the measured data, considering the influence of air temperature, air velocity and relative humidity, while for this approach either too many parameters are required or the functions cannot well follow the measured data.

(3) In addition to studying the moisture transfer mechanism in the materials, some researchers present more interests to define an intrinsic parameter, similar to the water absorption, to describe the drying rate. Krus et al. (2007) proposed to use the slope of duration of the first drying phase versus square root of sample height to measure the drying rate of building materials based on the simulations. Scheffler and Plagge (2010) used the experimental data to verify that it is more reasonable to adopt the duration of the second drying phase or the total drying time in the definition of drying coefficient. In the

\footnotetext{
* Corresponding author: jianhua.zhao@tju.edu.cn
} 
framework of conservation of built heritage, EN 16233 (2013) specifies a method for determination of the drying rates in the first and second drying phases of porous inorganic materials. The procedure specifies the test condition (the temperature and relative humidity), but does not state the air flow above the drying surface, which is quite important for the drying rate.

The above-mentioned studies investigated the drying behaviours of different building materials under the designed environmental conditions. The material functions are either taken from literature or generated from empirical functions. Limited research carried out material characterization by using the drying course to derive/calibrate material functions, which are actualy used in the HAM simulation.

In this paper, the drying behaviours of two building materials, ceramic brick and calcium silicate, were experimentally investigated. The influence of air flow above the drying surface and sample dimension on the drying rate is reported. The study explores how those factors affect the drying behaviour, thus provides a hint to analyze the moisture transfer in the buildings and control the moisture level to avoild potential impairs.

\section{2 concept of the drying}

Supposing the drying process occurs on the initially saturated material, vapour leaves from evaporation surface driven by vapour pressure difference until it gets equilibrium with the surrounding environment. The drying process is generally composed of two phases. In the first phase, the vapour pressure at the air-material interface keeps saturated until no more liquid is delivered onto the evaporation surface, which can be described as a linear line of the moisture loss versus time. The evaporation brings the cooling effect, thus the surface temperature decreases. This phase is mainly governed by the boundary condition. When there is no sufficient liquid conducted to the surface, the water front is receded from the evaporation surface into the material. The drying process steps to the second phase, during which moisture migrates to the surface by vapour diffusion. Thus, the drying rate slows down and the linear course starts to bend, companying with the rise of surface temperature. The drying rate in this phase mainly depends on the material property. The drying process of calcium silicate is exemplarily presented in Fig. 1.

\section{Experiment setup}

The drying behaviours of two building materials, calcium silicate (Casi) and ceramic brick (Bri), were experimentally studied. The samples were cutted into cylindrical shape as the symmetric structure is easier to analyze and to be implemented in 3D HAM simulation. To investigate the influence of sample dimension on the drying rate, the samples were prepared with different diameters and heights, as listed in Table 1. Each material owns two diameters: $53 \mathrm{~mm}$ and $88 \mathrm{~mm}$. For each diameter, calcium silicate is cut into the heights of $14 \mathrm{~mm}, 34 \mathrm{~mm}$ and $85 \mathrm{~mm}$, while ceramic brick has the heights of $20 \mathrm{~mm}$ and $41 \mathrm{~mm}$. Three samples are prepared for each dimension to account for the uncertainty.

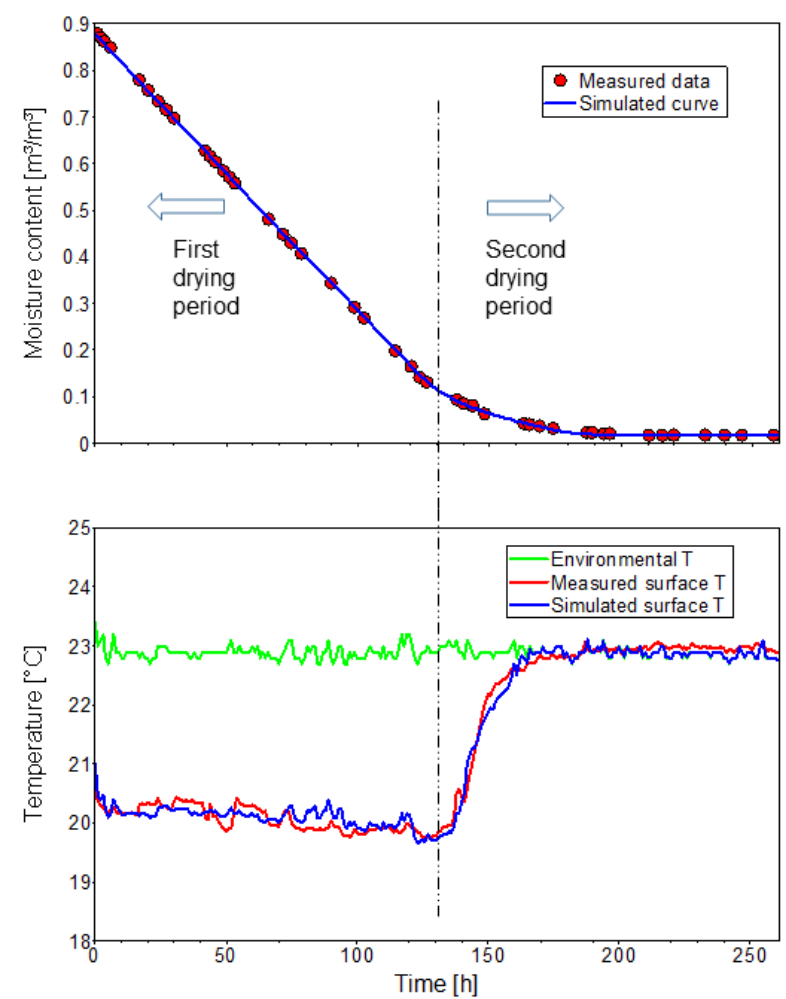

Fig. 1. The measured and simulated drying courses of calcium silicate (top). The measured and simulated surface temperature courses of calcium silicate and the relevant environmental temperature during the test (bottom). The simulation was carried out with Delphin 5 software.

Table 1. Variation of air flow velocity and sample dimension

\begin{tabular}{lcccc}
\hline Air flow velocity & $\mathrm{m} / \mathrm{s}$ & 0.4 & 1.2 & \\
Sample diameter & $\mathrm{mm}$ & 53 & 88 & \\
Sample height_Casi & $\mathrm{mm}$ & 14 & 34 & 85 \\
Sample height_Bri & $\mathrm{mm}$ & 20 & 41 & \\
\hline
\end{tabular}

\subsection{Sample preparation}

Samples were initially dried in the oven to obtain the dry mass and density. Thereafter, they were cooled down to the room temperature and sealed with aluminium foil on the lateral side. The bottom of sample was emerged in the water for one week and then the whole samples were soaked in the water for another week to get effective saturation. Then the sample was taken out and bottom of the sample was covered with aluminium foil to let moisture only to be dried out through the top surface.

\subsection{Drying apparatus}

The drying test was implemented by a specially designed drying apparatus with a wind tunnel to achieve a convective air flow above the material sample. The apparatus is enclosed with the hard PVC board, and the inlet and outlet of the tunnel are installed with three fans respectively to adjust the velocity of air flow in the tunnel. The bottom of the apparatus has the channels, 
which allow to pull in or draw out the sample holders. Before the measurement, the samples are placed in the sample holder that is further covered with the perforated plank, allowing only top surface of the samples to expose to the wind tunnel. Fig. 2 shows the schematic drawing of the drying apparatus with the sample holder. During the test, the sample is periodically taken from the sample holder and the mass loss of the sample is recorded. The wind channel can take up to maximum 12 samples in 4 sample holders in one test.

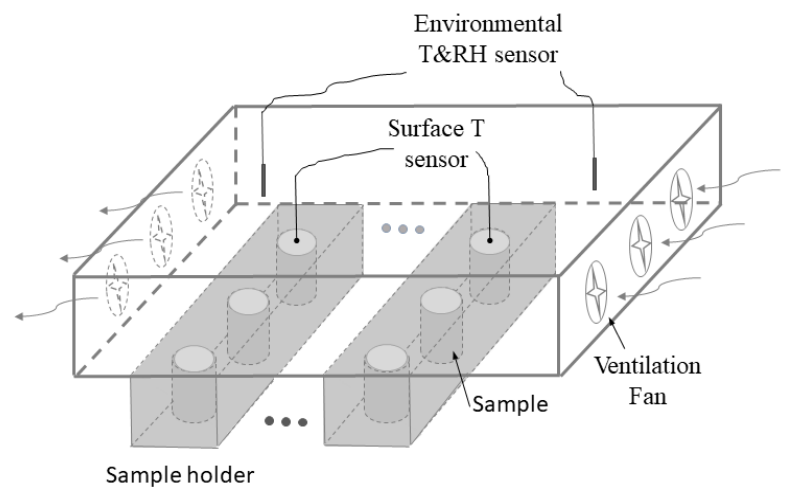

Fig. 2. Schematic drawing of drying apparatus.

The accurately reproducing the drying behaviour needs the realistic boundary condition. Due to the limited surface area of the sample, the surface heat transfer coefficient and mass transfer coefficient were both assumed uniformly distributed at evaporation surface. The surface temperature was measured at the surface center by the NTC sensor with the range of $-20^{\circ}$ $\mathrm{C}$ to $100^{\circ} \mathrm{C}$ and accuracy of $0.1^{\circ} \mathrm{C}$. The environmental temperature and relative humidity were recorded by the capacitive humidity sensors with the temperature range of $-20^{\circ} \mathrm{C}$ to $100{ }^{\circ} \mathrm{C}$ by accuracy of $0.1^{\circ} \mathrm{C}$ and humidity range of 0 to $100 \%$ by accuracy of $2 \%$. The air flow velocity in the channel was measured by the anemometer, with the measuring range of 0.2 to $20 \mathrm{~m} / \mathrm{s}$ by accuracy of $0.1 \mathrm{~m} / \mathrm{s}$. The temperature and relative humidity were recorded by a data logger at the time interval of 15 minutes. Two parallel tests were conducted in the same time, to differentiate the influence of surface air flow velocity on the drying rate. The average air flow speed in the tunnel was set as $0.4 \mathrm{~m} / \mathrm{s}$ and $1.2 \mathrm{~m} / \mathrm{s}$ respectively.

The drying apparatus was placed in an airconditioned room controlled under the temperature of 23 ${ }^{\circ} \mathrm{C}$ and relative humidity of $50 \%$.

\section{Results}

In the EN 16332, the amount of water remaining in the sample per unit area (in $\mathrm{kg} / \mathrm{m}^{2}$ ) at time $\mathrm{t}_{\mathrm{i}}$ is calculated as follows:

$M_{i}=\frac{m_{i}-m_{f}}{A}$
Where $m_{i}$ is the mass of the sealed specimen at time $t_{i}$ and $m_{f}$ is the final mass of the sealed specimen at time $t_{f}, A$ is the surface area.

Determination of the drying rate requires plotting the remaining water mass versus the time. The drying rate of the first drying phase corresponds to the negative slope of the initial linear section of the drying curve. The drying rate of the second drying phase corresponds to the negative slope of the linear section of the drying curve as a function of $\mathrm{t}_{\mathrm{i}}^{1 / 2}$ (EN16322).

To assess the influence of the sample height on the drying process, the drying rates of the first and second phases of calcium silicate with the surface diameter of $53 \mathrm{~mm}$ and different heights were calculated according to EN 16332 and presented in Fig. 3. The measurement was taken in three heights under the low air flow velocity: $14 \mathrm{~mm}, 34 \mathrm{~mm}$ and $85 \mathrm{~mm}$. Thus, they have also different initial masses. The remaining water masses in the sample as a function of time and the square root of the time were approximated by linear regression in order to obtain the best fit of the measured data points.

As shown in Fig. 3 left, the lower the sample is, the shorter the first drying period. The inflection point, which indicates the start of the second drying phase, is defined as the highest time point of two intersections of the linear regression line and drying curve in the plot of the mass flow rate as a function of square root of time (Fig 3. right). For the sample with the height of $85 \mathrm{~mm}$, the second drying phase starts after $15.7 \mathrm{~h}^{1 / 2}$, corresponding to $245.5 \mathrm{~h}$. Its drying rate of the second drying phase is 5.3193 . The $14 \mathrm{~mm}$ high one has the drying rate of 2.5026. Such results indicate the second drying rate becomes larger as the sample height increases.

Question rises for the method to determine the drying rate of the second drying phase described in EN 16322: the linear regression uses the most measured data in the first drying phase. Can this rate reflect the actual drying characteristic in the second drying phase?

In order to verify this, the drying flow rate as a function of moisture content is presented in Fig. 4 (top). The drying flow rate is determined by the water mass difference per unit time at unit area of drying surface area. For easy comparison, the moisture content as a function of time is also plotted in Fig. 4 (bottom). The graph shows that the sample with the height of $14 \mathrm{~mm}$ has the regression coefficient of 2.394, which is much larger than the $85 \mathrm{~mm}$ high one with the regression coefficient of 1.852. This means the higher the sample is, the lower the drying rate of the second drying phase. The same tendency can also be easily observed from Fig. 4 bottom, which indicates the higher the sample is, the longer second drying phase. This conclusion is in contradiction to the results presented in Fig 3. The approach in EN 16332 is not appropriate in determination of drying rate of the second phase. 

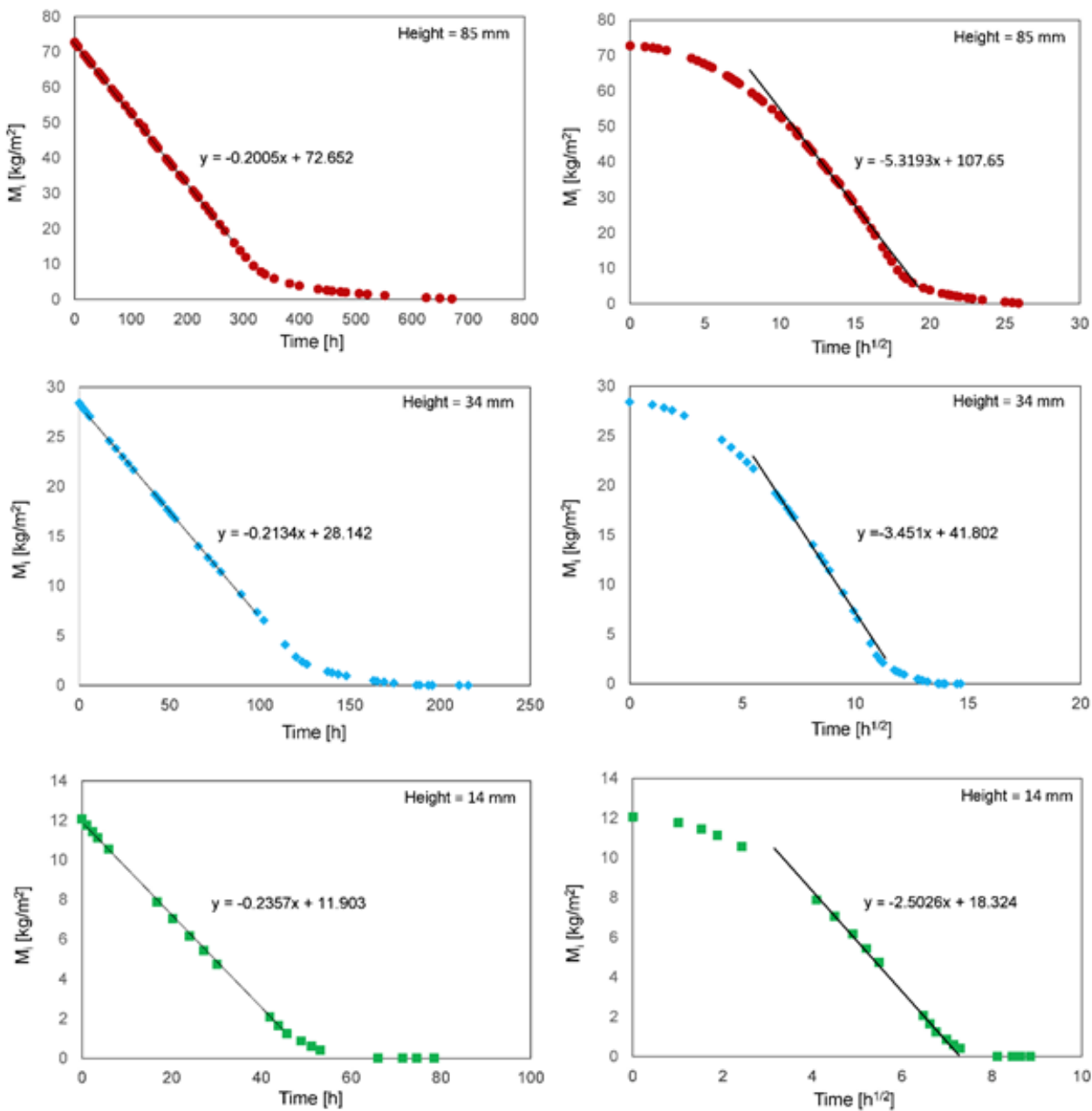

Fig. 3. The remaining water masses in the samples with different sample heights as a function of time (left) and as a function of square root of time (right) in order to calculate the drying rates of the first and second drying phases according to EN 16322.
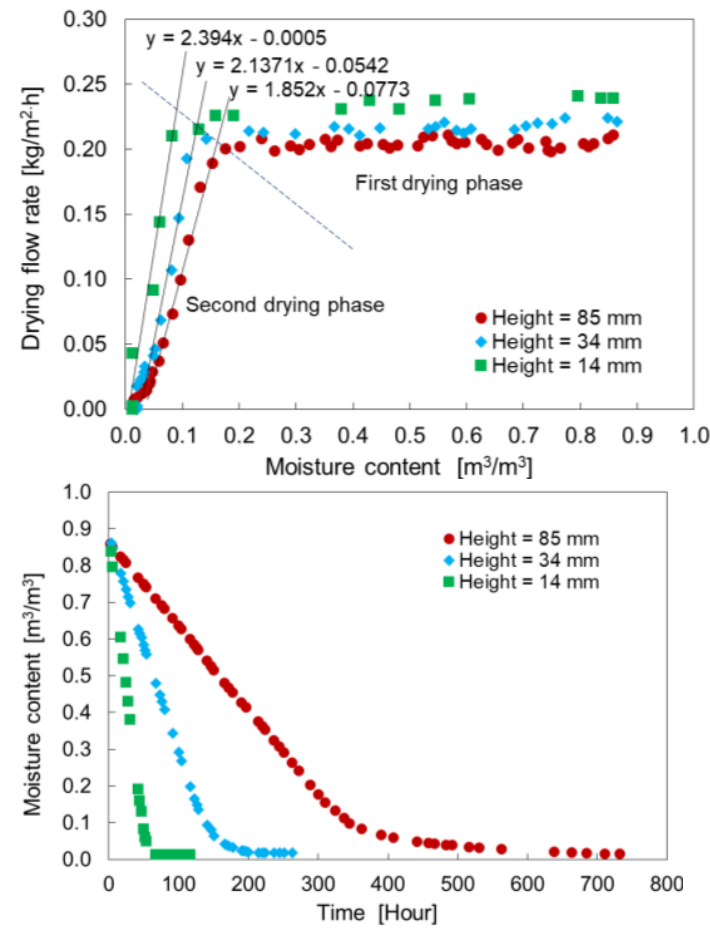

Fig. 4. Drying flow rates of calcium silicate with different sample heights as a function of moisture content (top) and moisture content in the samples as a function of time
Fig. 4 also indicates that the shorter the sample is, the lower moisture content the second drying phase starts at. The second drying phase of the $85 \mathrm{~mm}$ high sample starts at $0.16 \mathrm{~m}^{3} / \mathrm{m}^{3}$, while for the $14 \mathrm{~mm}$ high one, the starting moisture content is $0.09 \mathrm{~m}^{3} / \mathrm{m}^{3}$ and its second drying phase is much faster and shorter. One reason can be attributed to the lateral heat transfer: the ratio of the drying surface area and the lateral area is high for the shorter sample. Another reason is the short transport distance for moisture migration to the evaporation surface.

The influence of the surface area/diameter on the drying rate of calcium silicate is shown in Fig. 5. The fluctuation on the second drying period is due to the variation of relative humidity in the measurement room. The sample with the $53 \mathrm{~mm}$ diameter has a faster first drying phase and thus the second phase starts earlier compared to the one with the diameter of $88 \mathrm{~mm}$. The second drying phase of the smaller surface sample also begins at a higher moisture content.

\footnotetext{
*Corresponding author: jianhua.zhao@tju.edu.cn
} 

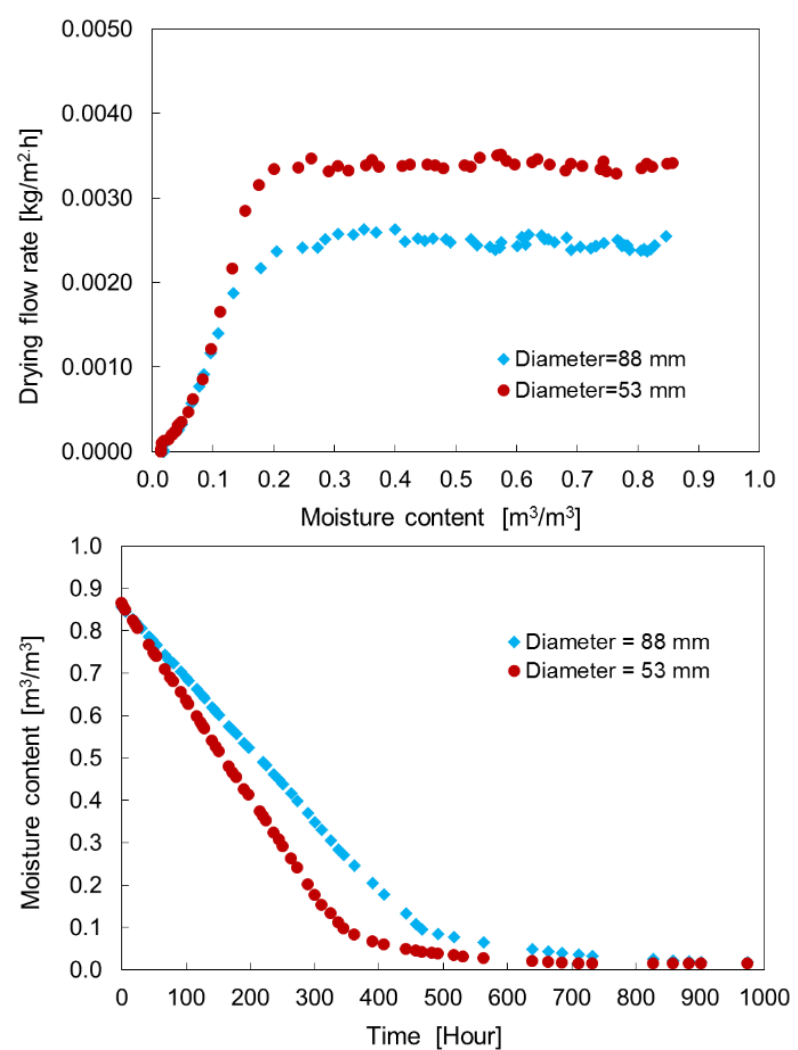

Fig. 5. Drying flow rate of calcium silicate with different surface diameters as a function of moisture content (top) and moisture content in the samples as a function of time (bottom).
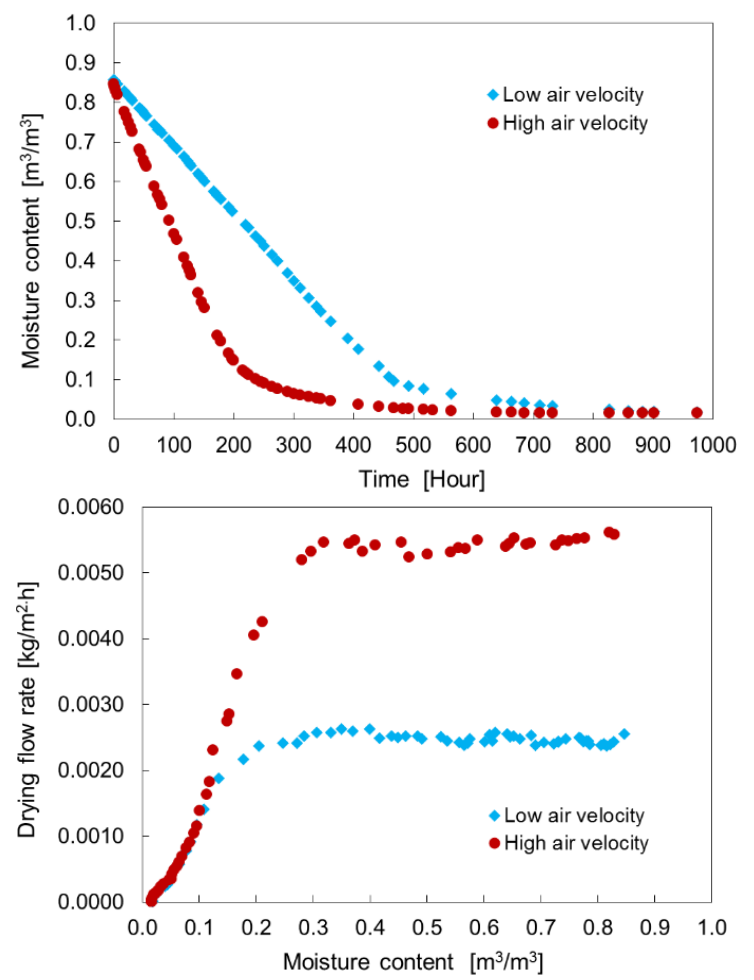

Fig. 6. Drying flow rate of calcium silicate with different surface air flow rates as a function of moisture content (top) and moisture content in the samples as a function of time (bottom)

The influence of the surface air flow on the drying rate of calcium silicate is presented in Fig. 6. The drying flow rate is governed by the air flow speed, and the environmental temperature and relative humidity. It can be represented by the mass transfer coefficient. A higher air flow on the material surface expedites moisture evaporation from the sample, thus leads to a larger mass transfer coefficient. It is also shown that the sample with the lower surface air flow velocity starts the second drying phase at a lower moisture content $\left(0.12 \mathrm{~m}^{3} / \mathrm{m}^{3}\right)$, compared to the one with a higher surface air flow velocity $\left(0.3 \mathrm{~m}^{3} / \mathrm{m}^{3}\right)$.
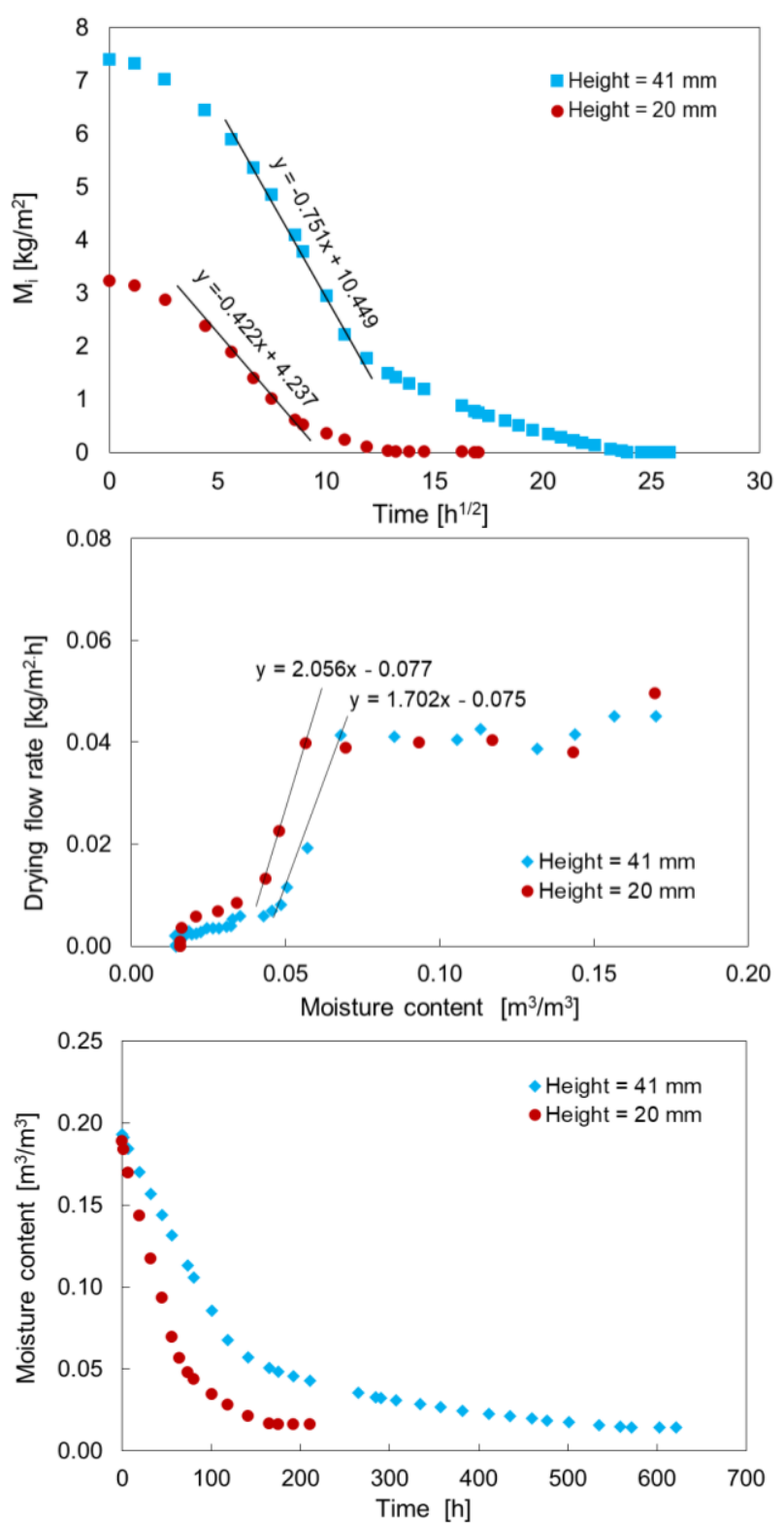

Fig. 7. Drying flow rates of ceramic brick with different sample heights derived according to EN16332 (top) and as a function of moisture content (middle). Moisture content in the samples as a function of time (bottom)

The impact of sample height on the drying flow rate of ceramic brick is presented in Fig.7. According to EN 16332 , the sample with the height of $41 \mathrm{~mm}$ has a larger drying flow rate of second drying phase than the one with $20 \mathrm{~mm}$ high one (Fig. 7 top). This is constrast to the results shown in the other two graphs in Fig.7. The conclusion is the same as that drawn from the measurement of calcium silicate: by using the linear section of the drying curve as a function of $t_{i}{ }^{1 / 2}$ to 
determine the drying rate of the second phase is not suitable.

The influence of the surface area/diameter on the drying rate of ceramic brick is presented in Fig. 8. The graphs show the surface area mainly impacts the drying rate of first drying phase.
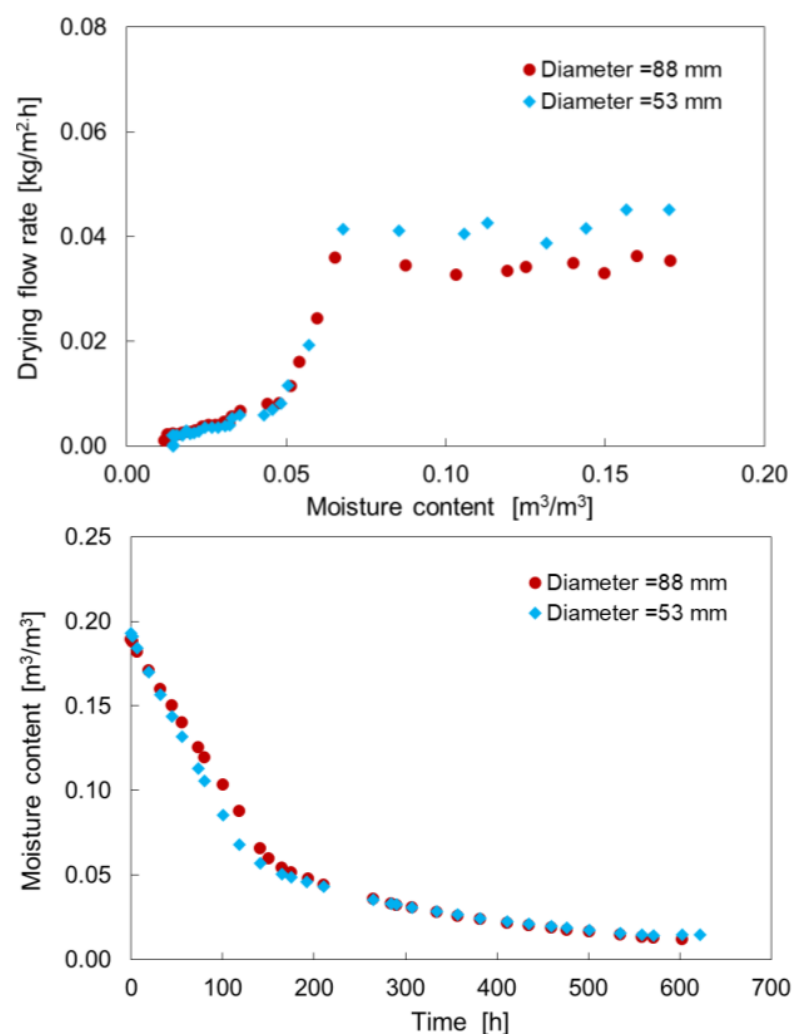

Fig. 8. Drying flow rates of ceramic brick with different surface diameters as a function of moisture content (top) and moisture content in the samples as a function of time

The influence of the surface air flow on the drying rate of ceramic brick is presented in Fig. 9. Similar to calcium silicate, a high surface air flow delivers a large drying rate.

\section{Conclusions}

The drying process of building material gives a great insight for moisture transport, thus provides the important calibration information during the material characterization. By the laboratory tests, the influence of the air flow velocity and the material dimension on the drying rate is investigated in this study. Air flow velocity on the evaporation surface has a large impact on the drying rate. The sample height mainly influences the second drying duration and the sample surface area/diameter impacts the first drying duration. The method using moisture flow rate versus moisture content is more appropriate in the assessment of the drying rate of the second drying period compared to the approach proposed in EN 16332.
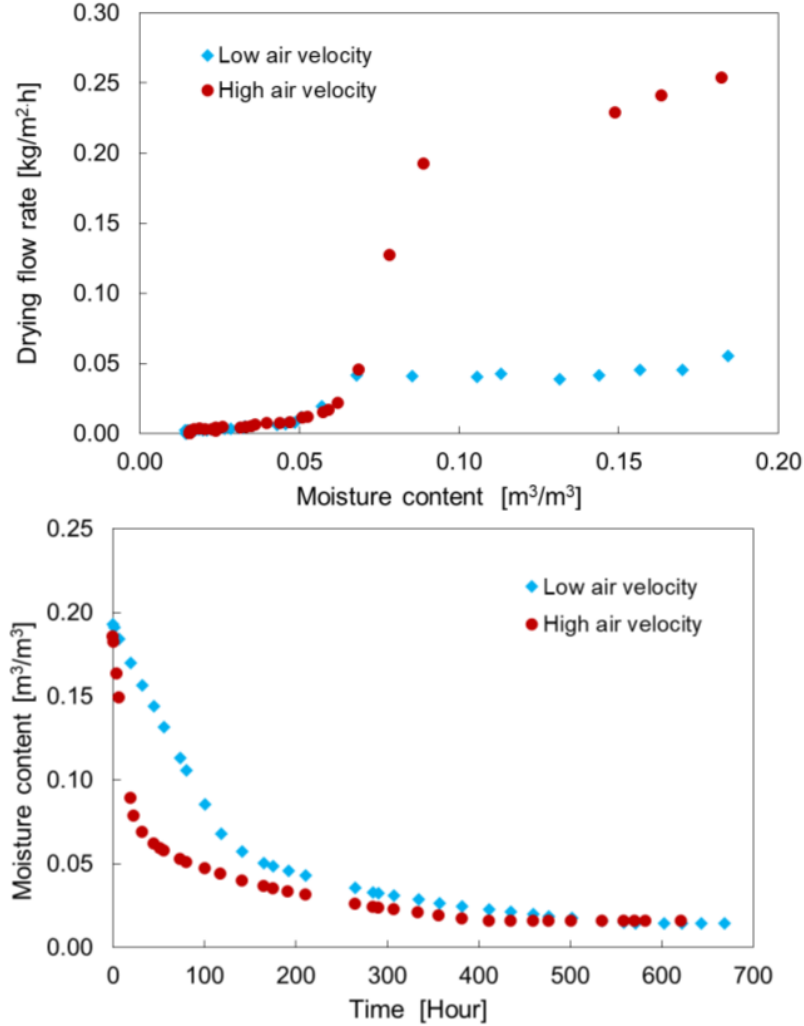

Fig. 9. Drying flow rates of calcium silicate with different surface air flow rates as a function of moisture content (top) and moisture content in the samples as a function of time

\section{References}

1. Kaya, O.Aydın, I. Dincer, Numerical modeling of heat and mass transfer during forced convection drying of rectangular moist objects. International Journal of Heat and Mass Transfer, Vol.49(1718), , pp.3094-3103, 2006.

2. C. Dietl, E.R.F. Winter, R. Viskanta. An efficient simulation of the heat and mass transfer process during drying of capillary porous, hygroscopic materials, Int. J. Heat Mass Transfer, Vol. 41, pp. 3611-3625, 1998.

3. M.B.Janettia, L. P.M.Colombo, F. Ochs, W. Feist. Effect of evaporation cooling on drying capillary active building materials. Energy and Buildings, Vol. 166, pp. 550-560, 2018.

4. G. A. Scheffler, R. Plagge. Introduction of a DryingCoefficient for Building Materials. American Society of Heating, Refrigerating and AirConditioning Engineers, Inc. ASHRAE. Buildings XI - Thermal Performance of the Exterior Envelopes of Whole Buildings: Proceedings, Paper 23, Atlanta, USA (2010)

5. Krus, M., Lenz, K., Plagge, R., Scheffler, G.: Ein Trocknungskoeffizient als neuer hygrothermischer Standardmaterialkennwert. 12. Symposium on Building Physics, Dresden University of Technology, Proceedings Vol. 1: 283-293, Dresden 2007. 
6. N. Karagiannis, M. Karoglou, A. Bakolas, M. Krokida, A. Moropoulou. Drying kinetics of building materials capillary moisture, Construction and Building Materials, Vol.137, 441-449, 2017.

7. EN 16322, Conservation of Cultural Heritage - Test Methods - Determination of Drying Properties, 2013.

8. Nicolai A (2007) Modeling and numerical simulation of salt transport and phase transition in unsaturated porous building materials. Phd, Syracuse University

9. Derdour L, Desmorieux H, Andrieu J (2000) A contribution to the characteristic drying curve concept: Application to the drying of plaster. Drying Technol 18(1): 237-260

10. Sander. A, Kardum, J.P., Skansi, D. Transport properties in drying solids, Poster session on drying, 14th international congress of chemical and process engineering, Prage, August 2000.

11. M. Van Belleghem, M. Steeman, A. Janssens, M. De Paepea, Drying behaviour of calcium silicate, Construction and Building Materials, Vol. 65, pp.507-517, 2014.

12. Jurk.k, Scheffer, G. Grunewald, J. Plagge. Durchführung und Analyse von Trockungsexperimenten von Baustoffen-Methoden, Funktionen und Parameter, Beitrag zum Feuchtetag, 2004.

13. E. Barreira, J.M.P.Q. Delgado, V.P. de Freitas, Wetting and Drying Kinetics of Building Materials, Drying and Wetting of Building Materials and Components, Springel, 2014.

14. K. Murugesan, K.N. Seetharamu, P.A.A. Narayana, A one dimensionalanalysis of convective drying of porous materials, Heat MassTransfer 32 (1996) 8188.

15. K.A. Landman. L.Pel and E.F. Kaasschieter, Analytic modelling of drying of porous materials. Mathematical engineering in industry, vol.8 (2), pp. 89-122, 2001. 